\title{
“Criando um problema”: a escrita da seção de identificação/caracterização do problema nas áreas de Linguística e Química
}

\author{
Camila Rayssa Barbosa da Silva* \\ Francisco Alves Filho** \\ Viviane Garcêz de Oliveira ${ }^{* * *}$
}

Resumo: Essa pesquisa objetivou analisar como a seção de caracterização/identificação do problema de projetos de pesquisa é organizada retoricamente nas áreas de Linguística e de Química. Com base em Swales (1990), Silva (2015) e Alves Filho (2018), foram analisados 9 projetos de pesquisa da área de Linguística e 9 da área de Química, produzidos para fins de pesquisa durante o curso de mestrado. Os resultados revelaram que, na seção em análise, a área de Química tende a apontar lacunas, enquanto a área de Linguística tende a levantar questionamentos sobre o tema.

Palavras-chave: Gêneros acadêmicos. Projetos de pesquisa. Seção de Caracterização do Problema. Análise de Gêneros.

Abstract: This research aimed to analyze how the problem characterization / identification section of the research project is rhetorically organized in the areas of Linguistics and Chemistry. Based on Swales (1990), Silva (2015) and Alves Filho (2018), 9 research projects from the Linguistics area and 9 from the Chemistry area produced for research purposes in the Master's degree were analyzed. The results revealed that, in the section under analysis, the area of Chemistry tends to point research gaps, while the area of Linguistics tends to raise questions about the theme proposed.

Keywords: Academic genres. Research project. Problem Characterization Section. Genre Analysis.

Résumé: Cette recherche vise à analyser comment la section de caractérisation/identification du problème dans le projet de recherche est organisé rhétoriquement dans les disciplines de Linguistique et de Chimie. Basé sur Swales (1990), Silva (2015) et Alves Filho (2018), 9 projets de recherche de Linguistique et 9 projets de Chimie, produit à des fins de recherche au Master ont été analysés. Les résultats montrent que, dans la section analysée, la discipline de Chimie a

\footnotetext{
* Mestranda em Letras com ênfase em estudos da Linguagem pela Universidade Federal do Piauí. Bolsista CAPES/FAPEPI. http://orcid.org/oooo-0001-8663-356X

${ }^{* *}$ Professor associado da Universidade Federal do Piauí. Doutor em Linguística pela Universidade Estadual de Campinas. http://orcid.org/o0oo-0002-2284-4197

*** Mestranda em Letras, na área de Linguística, pela Universidade Federal de Piauí. Bolsista CAPES/FAPEPI. http://orcid.org/oooo-00o1-6313-7715
}

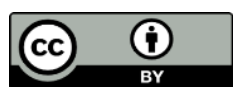

Este artigo está licenciado sob forma de uma licença Creative Commons Atribuição 4.0 Internacional, que permite uso irrestrito, distribuição e reprodução em qualquer meio, desde que a publicação original seja corretamente citada. 
tendance à indiquer les trous de recherche, tandis que la discipline de Linguistique a tendance à présenter les questions sur le thème.

Mots-clés : Genres universitaires. Projet de recherche. Section de caractérisation du problème. Analyse de Genres.

\section{Introdução}

O projeto de pesquisa é um gênero muito importante para a comunidade acadêmica, pois é utilizado em todas as áreas do conhecimento, já que serve como instrumento para auxílio e planejamento de pesquisa, além de servir como requisito para seleção em programas de pós-graduação e também para se pleitear financiamento em agências de fomento. $O$ fato de se tratar de um gênero que não é publicamente divulgado, necessitando de orientações vindas de membros mais experientes da academia, causa muitas dúvidas em seu processo de elaboração, sobretudo da parte de pesquisadores iniciantes, visto que cada comunidade discursiva o constrói de acordo com seus valores e práticas disciplinares.

Frente a essa problemática, analistas de gênero têm se debruçado em investigar a organização retórica das seções que compõem o projeto de pesquisa, com o intuito de despertar uma consciência retórica em pesquisadores iniciantes. Por exemplo, no Brasil, pesquisas já foram realizadas sobre o projeto de pesquisa a fim de analisar a seção de justificativa (ALVES FILHO, 2018; ALVES FILHO; OLIVEIRA, 2017; SILVA, 2015), a seção de metodologia (MONTEIRO, 2016; MONTEIRO; ALVES FILHO, 2018) e a seção de fundamentação teórica (RIO LIMA, 2015).

Para ampliar os estudos acerca do gênero projeto de pesquisa, este trabalho buscou analisar a seção de identificação/caracterização do problema de 9 projetos de pesquisa da área de Linguística e 9 da área de Química, para, assim como as pesquisas mencionadas, compreender a função retórica da referida seção, uma vez que não foram encontradas pesquisas relacionadas à seção de identificação/caracterização do problema. Como base teórica, nos amparamos nos pressupostos teórico-metodológico 
de Swales (1990) e, como ponto de partida para análise, no estudo de Alves Filho (2018), com o intuito de investigar as convergências e divergências entre as áreas em questão.

\section{A proposta de J. Swales para a análise de gêneros}

Swales (1990) se propôs a desenvolver um conceito de gênero que não se limitasse somente a fórmulas textuais, mas que também envolvesse o contexto de produção e a função social do gênero, pois pretendia que fosse revelado aos membros iniciantes como os gêneros funcionam retoricamente e por que são escritos do modo como são. Por esse motivo, a proposta de Swales mostrou-se ideal para o desenvolvimento dessa pesquisa, que visa analisar a seção de caracterização/identificação do problema de projetos de pesquisa escritos em duas áreas do conhecimento, Linguística e Química.

Swales (1990) desenvolveu conceitos-chave para a análise de gêneros, com o intuito de os aprendizes desenvolverem, de maneira bem-sucedida, a escrita de gêneros acadêmicos, considerando as práticas sociais que os envolvem, além das suas características formais. Os conceitos desenvolvidos por ele são o de gênero, como mencionado, o de comunidade discursiva e o de propósito comunicativo. Além disso, o autor também desenvolveu uma proposta teórico-metodológica para análise de gêneros, o modelo $C A R S^{1}$, que foi bastante replicado em pesquisas tanto no Brasil como internacionalmente.

O conceito de gênero proposto por Swales (1990) está ancorado em vários campos do conhecimento, o que fez com que o seu trabalho se tornasse original, já que considerava diversos aspectos da vida social. Nesse sentido, o conceito de gêneros numa perspectiva swalesiana foi idealizado a partir da influência de quatro áreas de estudo, a saber: linguística, folclore, literatura e retórica. A partir da contribuição desses quatro campos de estudos e do entendimento que o gênero é resultado das práticas sociais

\footnotetext{
${ }^{1}$ Create a Research Space
} 
recorrentes, Swales elaborou sua concepção de gênero voltado para o uso da linguagem em contextos específicos.

O autor elencou a ideia de classe, em que o gênero é uma classe de eventos comunicativos no qual a linguagem tem papel central. Essas classes de eventos são formadas, segundo Bawarshi e Reiff (2013), em resposta a um conjunto de propósitos comunicativos compartilhados pelos membros de uma comunidade discursiva. $\mathrm{O}$ propósito comunicativo é um critério privilegiado para definição do gênero e obedece a uma lógica subjacente, ou seja, para que a função do gênero seja atendida e os propósitos sejam alcançados, existem algumas escolhas de conteúdo, estilo e estrutura que devem ser seguidas para que um exemplar de texto se adeque aos critérios de pertencimento a determinado gênero.

A comunidade discursiva, por sua vez, é um grupo sociorretórico que atua em busca de objetivos comuns, compartilhados pelos membros que a compõem, separandoos por interesses afins, enfatizando mais o que as pessoas fazem e menos sua origem geográfica, e é central no conceito de gêneros proposto por Swales (1990), pois, os dois conceitos estão intimamente ligados, uma vez que os gêneros são utilizados pelos membros da comunidade discursiva para atingir objetivos comuns. Desse modo, o autor conclui que os gêneros emergem de comunidades discursivas, vinculando-se, dessa forma, a elas e não a indivíduos isolados.

Essa noção de comunidade discursiva tem sido importante para combater o prescricionismo, uma vez que, quem trabalha com comunidade discursiva, estabelece uma rede de conexão interdisciplinar, independente da área de atuação. A partir dessa conexão interdisciplinar, Swales (1992) explica que as variações sofridas nos gêneros são decorrentes das heterogeneidades disciplinares presentes nas diversas comunidades discursivas, por isso, afetam diretamente os gêneros e a sua produção.

Swales (1990) desenvolveu também o modelo CARS, que surgiu a partir de uma pesquisa realizada com o objetivo de analisar a organização retórica da seção de introdução de artigos de pesquisa, vindo a ser um modelo teórico-metodológico bastante disseminado para analisar diferentes gêneros.

O referido modelo é pautado nos conceitos de movimentos e passos retóricos. $\mathrm{O}$ movimento retórico consiste em unidades que possuem funcionalidade e finalidade no 
texto, ou seja, é uma unidade retórica ou discursiva que realiza função comunicativa coerente no discurso falado ou escrito (SWALES, 2004). Os passos retóricos, por sua vez, são unidades menores que realizam o movimento, e são opcionais ou obrigatórios. Neles estão contidos as intenções e estratégias do autor do texto, que são utilizadas para garantir o cumprimento das exigências do gênero, com o intuito de que sua função seja atingida.

Moreno e Swales (2018) reconhecem que parece haver menos consenso sobre como conceituar movimentos do que passos ao citar os seguintes exemplos: o rótulo para o movimento Background information or Information (in Peacock, 2002) é também chamado Occupying the niche, (in Berkenkotter \& Huckin, 1995), Reestablishing the territory, in Cotos et al., 2016; Contextualising the study, (in Kanoksilapatham, 2005, 2007) ou Highlighting overall research outcome, in Nwogu, 1997). Estas diferentes conceptualizações se relacionam tanto à diferente natureza das disciplinas (algumas de ciências sociais e outras de ciências naturais), como ao modelo original tomado como ponto de partida para a análise. Contudo, mesmo partindo de modelos diferentes, as nomeações são mais similares quando as análises se voltam para o nível dos passos (MORENO; SWALES, 2018, p. 43). A partir da reflexão anterior, defendemos que a noção de movimento se aplica melhor, a nosso ver, para corpora contendo textos resultantes de convenções retóricas bem sólidas, como é o caso de artigos de pesquisa de autoria de pesquisadores experientes e publicados em periódicos que apresentam instruções aos autores de modo bem definido. Alves Filho (2018, p.139) apresenta três argumentos para privilegiar nas análises de gênero a noção de passos:

a) o movimento retórico é uma categoria postulada pelo pesquisador a partir de uma generalização baseada em certa afinidade entre determinados passos retóricos; b) o passo retórico é uma categoria mais próxima da realidade retórica dos escritores de projetos; c) a teoria sociorretórica dá primazia para as práticas retóricas e para os modos como os próprios sujeitos concebem suas práticas.

Em função disso é que Alves Filho (2018), embora não deixe de reconhecer a relevância da noção de movimento retórico, opta por analisar projetos de pesquisa, gênero menos convencional do que artigos de pesquisa, fazendo uso 
da noção de passos sem vinculá-las a movimentos. O modelo de análise proposto por Swales (1990) foi utilizado por diversos pesquisadores tanto no Brasil como no exterior, que o adaptaram de acordo com as necessidades da peça genérica ou do gênero analisado. Podemos citar, como produções mais recentes, no Brasil, alguns trabalhos, como os de Trajano (2012) que analisa a organização retórica do gênero relato de caso publicados na área biomédica, Bezerra e Ritti-Dias (2014) que empreendeu uma análise da organização retórica de introduções de artigos científicos da área de saúde pública, Costa (2015) que propôs uma descrição sociorretórica de artigos acadêmicos experimentais em culturas disciplinares distintas, Monteiro (2016) e Monteiro e Alves Filho (2018) que analisam a seção de metodologia de projetos de pesquisa da área de Letras e Alves Filho (2018) que analisa a organização retórica da seção de justificativa de projetos de pesquisa da área de Letras.

Há também algumas produções anteriores e de grande importância para a Análise de Gêneros que utilizaram o modelo CARS, como o trabalho de Aranha (1996), em introduções de artigos de pesquisa; Motta-Roth (1995), em resenha de livros; Motta-Roth e Hendges (1996), em resumos de artigos de pesquisa; Juca (2006), na seção de justificativa de projetos de pesquisa de dissertação de mestrado; Bernardino (200o), em depoimentos de alcoólicos anônimos; Bezerra (2001) em resenhas acadêmicas, dentre outros.

Em decorrência da pertinência desses conceitos desenvolvidos por Swales (1990) para a análise de gêneros, vários pesquisadores se interessaram pelo gênero projeto de pesquisa, a fim de compreender como esse gênero é realizado em diferentes áreas do conhecimento. Nesse sentido, na próxima seção será discutida a concepção do gênero projeto de pesquisa e, em seguida, será discutido o projeto de pesquisa sob o ponto de vista da análise de gêneros.

\section{O projeto de pesquisa}


Conforme Motta-Roth e Hendges (2010), a atividade de pesquisa é realizada a partir da organização dos passos necessários para alcançar os objetivos traçados, ou seja, a atividade de pesquisa precisa de um planejamento prévio para que seja bem-sucedida. Esse planejamento, comumente, é chamado de projeto de pesquisa.

O gênero projeto de pesquisa apresenta itens lexicais, tais como conceitos, objetos e atores sociais, que possibilitam a identificação da respectiva área de conhecimento, e o caráter formal da linguagem, que contém termos técnicos ou abstratos e suas definições. Geralmente, têm em sua estrutura as seguintes seções: 1) Identificação ou dados do projeto, na qual temos o título e a área de pesquisa, o nome do autor e a instituição à qual ele pertence; 2) Identificação/caracterização do problema, que apresenta as hipóteses e perguntas da pesquisa; 3) Justificativa, em que o autor explica o motivo que o levou a pesquisar determinado tema; 4) Objetivos gerais e específicos, que evidencia o que se pretende conseguir com a realização da pesquisa; 5) Síntese da literatura relevante, que aborda os teóricos estudados que serviram de embasamento para a pesquisa em questão, demonstrando o que já se sabe; 6) Metodologia, que consiste na descrição dos recursos, materiais e procedimentos que foram utilizados para a execução da pesquisa; 7) Resultados ou impactos esperados que argumente sobre os possíveis benefícios esperados com o desenvolvimento da pesquisa, e 8) Cronograma, em que são delimitadas as datas para execução de cada etapa da pesquisa (MOTTA-ROTH; HENDGES,2010).

É importante destacar que as informações textuais e contextuais do gênero em questão propostas por Motta-Roth e Hendges (2010) não são fixas, podendo variar de acordo com a área do conhecimento, já que cada uma possui objetivos e objetos de estudo diferentes. Assim, no caso do nosso corpus, que é formado por projetos da área de Linguística e de Química, podemos perceber que, de acordo com os documentos de área da CAPES (Coordenação de Aperfeiçoamento de Pessoal de Nível Superior), a área de Química é uma ciência central, que impacta as diversas áreas do conhecimento, pois suas pesquisas tratam dos seres vivos, energia e meio ambiente. Já a área de Linguística aborda estudos linguísticos e interdisciplinares, que têm como objeto de estudo a língua e as práticas sociais envolvendo a linguagem. Nesse sentido, vale destacar que essas diferenças dos conteúdos que cada área discute gera diferenças também em sua maneira 
de argumentar sobre tais conteúdos, produzindo conhecimentos distintos na academia (OLIVEIRA, 2016). Ademais, cada área cria uma cultura, isto é, passa a ter convenções próprias e práticas discursivas específicas, fazendo com que cada uma tenha o seu modo de elaborar conhecimentos, a partir da sua própria maneira de estabelecer epistemologias. Portanto, resumidamente, compreendemos que cada área do conhecimento tem a sua própria cultura disciplinar, o que faz com que identifiquemos a comunidade discursiva a qual ela pertence.

Essa diferença entre as áreas, no que diz respeito ao objeto de estudo, acarreta diferentes modos de fazer pesquisa, que afeta diretamente a elaboração do projeto, isto é, dependendo da pesquisa, se é de campo, laboratorial ou bibliográfica, há variações na organização retórica do projeto (MOTTA-ROTH; HENDGES,2010). Além disso, há uma diferenciação que diz respeito ao modo como a área condiciona o olhar do pesquisador para o objeto de análise, que está diretamente relacionado ao fazer científico e como este é concebido.

Nesse sentido, cabe trazermos a discussão sobre os tipos de história propostos por Koerner (2014), o qual explica como o conhecimento científico é construído a partir da percepção sobre o objeto. Conforme esse autor, há quatro tipos de história, a saber: a história-resumo; a história propagandística; a história crítica e a historiografia.

O primeiro tipo de história de Koerner (2014), a história-resumo, faz um panorama da disciplina, a fim de mostrar como ocorreu seu desenvolvimento. Nesse tipo de abordagem, a história é vista como um progresso, sendo construída a partir de grandes feitos e grandes nomes. O segundo tipo, que reconta o passado apontando seus erros para construir um presente grandioso, fazendo uma espécie de propaganda, equivale à história propagandística, a qual julga e condena o passado para que os mesmos erros não possam ser cometidos no presente. O terceiro tipo de história apresentado é a história crítica, na qual se busca fazer uma história “desinteressada”, que não faz juízo de valor sobre o passado, procurando mostrá-lo como realmente foi. E, por fim, o quarto tipo de história que é denominado de historiografia, no qual se defende um modo de fazer história que proporcione uma compreensão dos fatos linguísticos baseados em sua evolução e no momento em que foram produzidos, e que, além disso, permita que não 
sejam cometidos no presente os mesmos erros do passado, evidenciando continuidades e descontinuidades na construção do conhecimento.

Essa discussão sobre o fazer científico através dos tipos de histórias nos permite compreender melhor as convergências e divergências entre as áreas de Linguística e Química, pois, a partir do modo como cada área elabora as seções do projeto de pesquisa, especificamente a seção de identificação/caracterização do problema, é possível ter uma noção de como elas veem o fazer científico.

\section{O projeto de pesquisa sob a perspectiva da Análise de Gêneros}

O projeto de pesquisa tem sido motivo de análise de alguns estudiosos de gêneros, primeiro pelo fato de ser pouco pesquisado e também pela necessidade de compreender como ele é organizado retoricamente em diferentes comunidades discursivas. Decorrente disso, alguns trabalhos envolvendo o gênero projeto de pesquisa já foram realizados no Brasil.

Podemos citar os trabalhos de Silva (2015), no qual a autora analisou a recorrência de movimentos e passos na seção de justificativa de projetos de pesquisa da área de História, evidenciando que a seção de justificativa é composta por três movimentos retóricos cujas funções são indicar as motivações para a realização da pesquisa/escolha do tema, mostrar a relevância da pesquisa e indicar a viabilidade da pesquisa, sendo realizados por doze passos.

Outro importante trabalho é o de Alves Filho e Oliveira (2017), em que analisaram a organização retórica da seção de justificativa do gênero pré-projeto de mestrado dos Programas de Pós-graduação em Letras/Linguística e História, demonstrando que há convergências e divergências na maneira em que cada área elabora a seção de justificativa. Por exemplo, na área de História, os mestrandos tendem a levantar mais problemas para justificar sua pesquisa, enquanto na área de Linguística os mestrandos preferem destacar os benefícios que a pesquisa poderá trazer para a sociedade e/ou comunidade. 
A pesquisa realizada por Alves Filho (2018), que versa sobre a organização retórica da seção de justificativa de pré-projetos de pesquisa de autoria de egressos de cursos de Linguística em situação de submissão a cursos de mestrado, evidencia a presença de três passos que ainda não haviam sido descritos na literatura sobre esta seção: definindo conceitos, explicando fenômenos e rescrevendo e/ou recomendando ação empírica, além desses, outros passos também foram encontrados, como: indicar lacuna, reportar pesquisa prévia e indicar indagações de pesquisa.

A investigação de Monteiro (2016) e Monteiro e Alves Filho (2018), com foco na seção de metodologia em projetos de Letras/Linguística, constatou a existência de quatro movimentos na referida seção: 1) apresentando abordagem teórica-metodológica da pesquisa; 2) descrevendo a etapa de revisão bibliográfica; 3) descrevendo a etapa de coleta de dados e 4) descrevendo a etapa de análise dos dados. O movimento 3 foi o mais presente nos textos analisados, tanto em termos de extensão quanto na diversidade de passos empregados para sua realização, enquanto que o movimento 2 apresentou-se de modo bastante resumido e generalizado.

As pesquisas aqui descritas, no geral, descrevem e analisam os passos e movimentos retóricos mais recorrentes em seções específicas de projetos de pesquisa, com base na proposta teórico-metodológica de Swales (1990), o modelo CARS, com o intuito de proporcionar uma consciência retórica sobre o gênero em questão. Diante disso, podemos perceber que, embora as discussões desses trabalhos se voltem para seções diferentes, ainda não há pesquisas voltadas para a seção de identificação/caracterização do problema. Então, pelo fato de entendermos que todas as seções que compõem o projeto de pesquisa exercem uma função importante para que esse gênero atinja seus propósitos comunicativos e que todas possuem suas particularidades, escolhemos a seção de identificação/caracterização do problema como objeto de análise, tendo como propósito conhecer como as áreas de Linguística e de Química organizam retoricamente essa seção.

\section{A seção de identificação/caracterização do problema}


A seção de identificação/caracterização do problema de um projeto de pesquisa corresponde à fase inicial de um projeto, pois é nela que se busca um problema a ser solucionado com a realização da pesquisa. No entanto, cabe perguntar: o que seria um problema de pesquisa científico?

Segundo Gil (2002), um problema de pesquisa de caráter científico é sempre uma questão ainda não resolvida e que é objeto de discussão em qualquer âmbito do conhecimento. Essa questão não deve ser relacionada a valores, tais como medir se pessoas de determinada cultura são honestas ou não, mas sim a fatos empíricos, livres de percepções pessoais, como investigar os fatores que contribuem para a alfabetização de crianças até 6 anos de idade. Nesse sentido, Gil (2002) afirma que formular um problema de pesquisa não é uma tarefa fácil e necessita de condições que facilitem o processo criativo. Assim, deve haver uma imersão sistemática no objetivo, em que o pesquisador deve conhecê-lo o máximo possível, além disso, é imprescindível que haja um estudo da literatura existente sobre a temática, bem como conversar com pesquisadores que possuem experiência tanto na área a ser pesquisada como em formular problemas de pesquisa.

Gil (2002) argumenta que esse contato com pesquisadores experientes é importante, pois permite que se tome conhecimento de regras facilitadoras para formular o problema, tais como centrá-lo em uma pergunta baseada em fatos empíricos, e, além disso, deve-se pensar na viabilidade e na delimitação de uma dimensão possível para o problema. É importante ressaltar que esse contato com pesquisadores experientes faz com que a problemática seja elaborada em conformidade com a área em que o projeto de pesquisa está inserido, o que pode seguir as regras postas por Gil (2002) ou não, uma vez que cada área possui suas particularidades ao conceber um gênero.

Em consonância com Gil (2002), Motta-Roth e Hendges (2010) entendem que a seção de caracterização do problema delimita o que se quer estudar especificamente, a partir de um questionamento para o qual se busca respostas por meio da pesquisa. Esse problema surge com base no tema do projeto a ser investigado. Dessa forma, é útil pensar que o problema de pesquisa deve ser respondido a partir de uma investigação, ou 
seja, nessa seção, segundo Barros (2005), o pesquisador deve esclarecer qual é o objeto de sua pesquisa, respondendo ao questionamento “o que fazer?”.

Para se chegar a esse questionamento, Heerdt e Leonel (2007) defendem que deve haver uma contextualização do tema de pesquisa, de modo que a situação ou o contexto no qual o problema está inserido introduza o leitor no tema, permitindo uma visualização situacional da questão. Nesse sentido, este trabalho buscou investigar como o problema de pesquisa é construído nas áreas de Linguística e Química, com o intuito de evidenciar o que é mais valorizado em uma ou outra área, e o que é semelhante ou divergente entre elas.

\section{Metodologia}

Para analisar e descrever a seção de identificação/caracterização do problema de projetos de pesquisa, escritos por pesquisadores iniciantes, foi utilizado um corpus de 18 projetos de pesquisa como amostra, sendo 9 da área de Linguística e 9 da área de Química. Os projetos foram cedidos pelos próprios mestrandos.

Foram selecionados apenas projetos que possuíam a seção intitulada de “caracterização do problema”, na área de Química, e de “identificação do problema”, na área de Linguística. Os nomes dos autores dos projetos foram suprimidos, e cada projeto recebeu uma nomenclatura que obedece à seguinte forma: PPQ, seguida de um número sequencial, para projetos de pesquisa da área de Química, e PPL, seguida do número sequencial, para a área de Linguística.

Para realizar as análises propriamente ditas, inicialmente foi feita uma leitura integral dos projetos para compreender a organização das seções do projeto e a proposta de cada uma delas. O segundo momento foi dedicado inteiramente à seção de identificação/caracterização do problema, a fim de identificar quais as estratégias retóricas eram utilizadas pelos escritores, ou seja, procuramos identificar os passos retóricos mais recorrentes na referida seção. 
Para identificar os passos retóricos, partimos da proposta de Alves Filho (2018). Assim como o referido autor, optamos por analisar e descrever somente os passos retóricos, deixando de lado a ideia de movimento. Tal opção se justifica pelo seguinte: a) a seção sob análise possui extensão curta, e por isso não apresenta funções retóricas e comunicativas amplas o suficiente para serem categorizadas como movimentos; b) a análise prévia revelou a presença de unidades informacionais de natureza muito variada (aspecto metodológico, teórico, empírico), o que torna inviável propor generalizações a nível de movimento retórico de modo elucidativo, econômico e funcional. Tendo em vista o corpus de análise, a análise apenas de passos se mostra mais adequada (Tabela 1).

Após a identificação dos passos retóricos nas seções em análise das referidas áreas, buscamos fazer um comparativo entre as duas organizações retóricas, a fim de perceber semelhanças e diferenças. Após descrever os passos retóricos e traçar um comparativo entre as duas áreas, foi feita uma reflexão sobre o fazer científico, buscando evidenciar as diferentes visões de ciência presentes em cada uma delas.

\section{Resultados e discussão}

As análises das 18 seções de identificação/caracterização do problema indicaram a recorrência de dez passos retóricos (Tabela 1), os quais já foram descritos por Alves Filho (2018). Dentre esses dez passos, apenas cinco foram comuns às duas áreas de Linguística e Química. Não foi encontrado nenhum passo retórico que ainda não houvera sido descrito em pesquisas anteriores. $\mathrm{O}$ que se distanciou notadamente foi a forma como esses passos foram realizados em cada área, ou seja, os passos refletiram os valores presentes tanto na área de Química como na área de Linguística.

Dessa maneira, foi possível perceber a diferença de como as duas áreas do conhecimento concebem o fazer científico, que será mostrado no decorrer da explanação das análises.

Tabela 1 - Passos retóricos recorrentes na seção de identificação/caracterização 
do problema na área de Linguística e Química

\begin{tabular}{|l|c|c|}
\hline \multicolumn{1}{|c|}{ Passos retóricos } & Linguística & Química \\
\hline Apresentando objetivos da pesquisa & $6 / 9$ & $7 / 9$ \\
\hline Explicando fenômeno & $7 / 9$ & $4 / 9$ \\
\hline Indicando problemas no mundo real & $5 / 9$ & $7 / 9$ \\
\hline Relatando pesquisa prévia & $4 / 9$ & $7 / 9$ \\
\hline Indicando lacunas da pesquisa & $3 / 9$ & $7 / 9$ \\
\hline Justificando seleção do corpus & & $3 / 9$ \\
\hline $\begin{array}{l}\text { Caracterizando a abordagem metodológica da } \\
\text { pesquisa }\end{array}$ & & $3 / 9$ \\
\hline Justificando relevância da pesquisa & & $7 / 9$ \\
\hline Indicando indagações da pesquisa & $8 / 9$ & \\
\hline Inserindo-se numa área de pesquisa & $3 / 9$ & \\
\hline
\end{tabular}

Fonte: elaboração dos pesquisadores

Por meio da observação da Tabela 1, podemos perceber que o passo mais recorrente nas duas áreas é “Apresentando objetivos da pesquisa”. Esse passo é reiterado em, praticamente, todas as seções dos projetos de pesquisa das áreas de Linguística e de Química. Isso mostra a centralidade desse passo na seção em questão, já que apresentar objetivos evidencia a relevância da pesquisa em todas as seções, mesmo que exista uma seção específica, no caso, a seção de objetivos, que se faz presente nos projetos das duas áreas. Isso acontece com frequência na seção de caracterização do problema, como podemos ver nos exemplos PPLo4 e PPQo1, a seguir.

[PPLo4] "Por essa razão, esta pesquisa se propõe a analisar a constituição multimodal de e-books disponibilizados em blogs de instituições privadas de ensino superior brasileiras, conteúdos esses que estão inseridos dentro do marketing de conteúdo, buscando, ao mesmo tempo, descobrir o papel da multimodalidade na formulação dos conteúdos.”

[PPQo1] “Assim, em continuidade aos estudos com esta espécie, este trabalho tem como objetivo isolar e identificar princípios bioativos, bem como quantificar os flavonoides rutina e quercetina nos extratos e frações das folhas, cascas dos frutos e sementes de S. acuruensis." 
É importante ressaltar que a realização desse passo, geralmente, ocorre de maneira explícita, ou seja, são utilizadas pistas linguísticas, como "esta pesquisa se propõe a analisar" (PPLo4) e "tem como objetivo" (PPLo1), que facilitam a sua identificação.

Outro passo recorrente tanto em Linguística quanto em Química é "Explicando fenômeno", que visa explicitar, segundo Alves Filho (2018), fenômenos empíricos com base no que já é sabido. Além disso, o autor menciona que esse passo reflete o propósito com o qual a leitura de estudos prévios é realizada, no caso, com o propósito de ler para resenhar e confirmar fenômenos já consolidados em uma determinada área do conhecimento.

$\mathrm{Na}$ área de Linguística, como já mencionado, os autores dos projetos explicam fenômenos já consolidados na área em que a pesquisa se insere, os quais podem ser decorrentes de resultados de pesquisas anteriores, porém não fica explícita essa referência através de citações diretas ou indiretas. Uma possível justificativa para a realização desse passo sem apontar uma referência a pesquisas anteriores pode ser o fato de que o projeto de pesquisa é voltado para leitores que já possuem conhecimento acerca do tema de pesquisa. Para exemplificar esse passo, a seguir está posto o exemplo PPLo3, que relata fenômenos empíricos com base no que já se sabe.

[PPLo3] "O Português Brasileiro é resultado de inúmeras influências linguísticas sofridas ao longo do seu processo de formação. As línguas africanas são um exemplo dessas influências e, desde o século XVI, começaram a atrair o interesse científico de estudiosos."

Diferentemente do que foi posto na área de Linguística, os autores dos projetos da área de Química costumam realizar esse passo sempre com base em pesquisas anteriores citadas explicitamente, ou seja, há sempre uma citação direta ou indireta, reportando uma pesquisa que tratou de tal tema. No exemplo abaixo, essa referência é feita pelo número [1], que representa uma citação indireta.

[PPQo6] "Nos últimos anos os padrões de alimentação estão sofrendo transformações mundialmente, em especial nos países emergentes como o Brasil e, sobretudo no setor agroalimentar onde o processo de globalização e 
o desenvolvimento de novas tecnologias têm favorecido a substituição de alimentos in natura ou minimamente processados de origem vegetal como frutas, sementes, nozes, raízes, legumes e verduras por alimentos processados e/ou ultraprocessados. ${ }^{[1]}$ "

Quando comparamos a presença dos passos nas duas áreas vemos que o passo "Explicando um fenômeno" é o único mais recorrente em linguística. Os demais passos: "Indicando problemas no mundo real", "Relatando pesquisas prévias" e "Indicando lacunas de pesquisa” são mais recorrentes em Química. Já o passo “Apresentando objetivos da pesquisa” possui quase a mesma recorrência.

O passo "Indicando problemas no mundo real”, que tanto na área de Química como na área de Linguística está relacionado à motivação da pesquisa, possui realizações diferentes em cada uma delas. Assim, na área de Linguística, indica um problema que geralmente parte do empírico, ou seja, como explica Alves Filho (2018), menciona problemas da vida prática que podem ser sanados com a realização da pesquisa, sem estar atrelado a pesquisas anteriores, como mostrado a seguir:

[PPLo2] "Há muitas décadas, o ensino de Língua Portuguesa (doravante LP) em geral e o ensino de gramática em particular têm sido objetos de crítica de muitos especialistas da área. No entanto, mesmo com esse intenso movimento crítico, pode-se dizer que os avanços no ensino ainda são incipientes, apesar da volumosa produção científica sobre o ensino de LP em vários aportes teóricos."

Já na área de Química, os problemas de pesquisa são comumente oriundos de outras pesquisas, ou seja, os autores dos projetos tendem a buscar em pesquisas já realizadas problemas que não foram resolvidos ou problemas que foram constatados com a realização da pesquisa, mas que não foram solucionados definitivamente.

[PPQ04] “Os níveis de metais pesados no meio ambiente têm aumentado nas últimas décadas devido à atividade industrial [1]. Embora estas atividades proporcionem um aumento positivo no desenvolvimento econômico, trazem também grandes problemas devido à liberação de produtos prejudiciais ao meio ambiente e ao organismo humano [1]." 
Semelhante à área de Química, houve apenas uma ocorrência de indicação de problema no mundo real vinculada à pesquisa anterior na área de Linguística.

[PPLo8] "No entanto, na prática universitária, isso parece não recorrer frequentemente. Queiroz, Bessa e Jales (2015) concluem em sua pesquisa sobre a produção textual acadêmica no curso de Letras-português que professores e alunos ainda não dialogam o suficiente rumo a constituir conhecimentos de ordem teórica e prática sobre os gêneros acadêmicos recorrentes em sua área."

Num projeto de pesquisa há uma expectativa de que os autores dos projetos indiquem lacunas, pois, segundo Barros (2005), a necessidade de preencher lacunas mostra a originalidade da pesquisa, e, além disso, estabelece conexão com outras pesquisas e com o mundo externo, sendo um argumento relevante para a realização da pesquisa. No passo "Indicando lacunas de pesquisa", os argumentos utilizados pelos autores para explicar o que deflagrou a pesquisa normalmente englobam o apontamento de aspectos nunca contemplados sobre determinado tema ou aspectos que foram considerados insuficientes em uma pesquisa anterior, como podemos ver nos exemplos abaixo.

[PPLo2] "Embora a capacidade de interpretação multimodal seja importante tanto no âmbito de materiais impressos quanto digitais, envolvendo ambientes escolares ou não, evidencia-se, por meio de pesquisas, que os estudos sobre multimodalidade em gêneros característicos da internet ainda precisam ser mais realizados (ARAÚJO,2011, p. 22)."

[PPQ04] "Encontramos na literatura várias aplicações de derivados de naftalimidas na investigação de diferentes sistemas [7,8,9,10,11]. No entanto, nenhum discute o emprego de um sensor eletroquímico de filmes automontados de derivados de naftalimidas formados com técnica de automontagem camada-por-camada ou Layer-by-Layer (LbL) [12]."

No entanto, esse passo foi menos recorrente na área de Linguística comparado à área de Química, o que pode ser explicado, segundo Alves Filho (2018), pelo fato de este ser um passo que geralmente se baseia na leitura de outras fontes bibliográficas, e sugere, 
dessa forma, que as leituras feitas por pesquisadores iniciantes, na área de Linguística, são orientadas mais frequentemente para o propósito de ler e resumir textos. Além disso, essas fontes, na maioria dos casos, são livros e/ou capítulos de livros já consolidados na área de pesquisa na qual estão inseridos. Assim, a leitura é pouco voltada para artigos publicados em periódicos que trazem pesquisas recente relacionadas ao tema sob investigação, ocasionando numa escrita na qual quase não são feitas análises críticas às pesquisas recentes na área. Teses e dissertações também são pouco exploradas, o que pode observado na Tabela 2.

Tabela 2 - Tipos de fontes bibliográficas mais utilizadas como embasamento de pesquisa na área de Linguística

\begin{tabular}{|c|c|c|c|c|}
\hline PROJETO & ARTIGO & DISSERTAÇÃO & TESE & $\begin{array}{c}\text { LIVRO OU CAPÍTULO } \\
\text { DE LIVRO }\end{array}$ \\
\hline $\begin{array}{l}\text { PPLo2 } \\
(2017)\end{array}$ & $\begin{array}{c}2 \\
\text { PUBLICADOS EM } \\
1996 \text { E } 2010\end{array}$ & & & $\begin{array}{c}12 \\
\text { PUBLICADOS ENTRE } \\
1949 \text { E } 2015\end{array}$ \\
\hline $\begin{array}{l}\text { PPLo3 } \\
(2017)\end{array}$ & $\begin{array}{c}4 \\
\text { PUBLICADOS } \\
\text { ENTRE 2004 E } 2014\end{array}$ & & & $\begin{array}{c}12 \text { PUBLICADO ENTRE } \\
1950 \text { E } 2015\end{array}$ \\
\hline $\begin{array}{l}\text { PPLo4 } \\
(2017)\end{array}$ & $\begin{array}{c}6 \\
\text { PUBLICADOS } \\
\text { ENTRE } 2011 \text { E } 2017\end{array}$ & & $\begin{array}{c}1 \\
\text { PUBLICADA } \\
\text { EM } 2017\end{array}$ & $\begin{array}{c}2 \\
\text { PUBLICADOS EM } 2008 \\
\text { E } 2013\end{array}$ \\
\hline $\begin{array}{l}\text { PPLo5 } \\
(2017)\end{array}$ & $\begin{array}{c}3 \\
\text { PUBLICADOS } \\
\text { ENTRE } 2010 \text { E } 2015\end{array}$ & $\begin{array}{c}1 \\
\text { PUBLICADA EM } \\
2005\end{array}$ & $\begin{array}{c}2 \\
\text { PUBLICADAS } \\
\text { EM } 2012 \\
\end{array}$ & $\begin{array}{c}3 \\
\text { PUBLICADOS ENTRE } \\
2003 \text { E } 2014\end{array}$ \\
\hline $\begin{array}{l}\text { PPLo6 } \\
(2017)\end{array}$ & $\begin{array}{c}3 \\
\text { PUBLICADOS } \\
\text { ENTRE } 1973 \text { E } 2000\end{array}$ & $\begin{array}{c}3 \\
\text { PUBLICADAS } \\
\text { ENTRE } 1977 \text { E } 1999\end{array}$ & $\begin{array}{c}4 \\
\text { PUBLICADAS } \\
\text { ENTRE } 1978 \text { E } \\
\mathbf{2 0 0 9}\end{array}$ & $\begin{array}{c}7 \\
\text { PUBLICADOS ENTRE } \\
1974 \mathrm{E} \\
\mathbf{2 0 0 8}\end{array}$ \\
\hline $\begin{array}{l}\text { PPLo7 } \\
(2016)\end{array}$ & $\begin{array}{c}4 \\
\text { PUBLICADOS } \\
\text { ENTRE } 1988 \text { E } 2012\end{array}$ & $\begin{array}{c}2 \\
\text { PUBLICADAS EM } \\
1992 \text { E } 2009\end{array}$ & $\begin{array}{c}3 \\
\text { PUBLICADAS } \\
\text { ENTRE } 2002 \text { E } \\
\mathbf{2 0 1 4}\end{array}$ & $\begin{array}{c}14 \\
\text { PUBLICADOS ENTRE } \\
1998 \text { E } 2015\end{array}$ \\
\hline $\begin{array}{l}\text { PPLo8 } \\
(2017)\end{array}$ & $\begin{array}{c}1 \\
\text { PUBLICADO EM } 2015\end{array}$ & & & $\begin{array}{c}5 \\
\text { PUBLICADOS ENTRE } \\
1984 \text { E } 2010\end{array}$ \\
\hline $\begin{array}{l}\text { PPLo9 } \\
(2016)\end{array}$ & $\begin{array}{c}1 \\
\text { PUBLICADO EM } 2015\end{array}$ & $\begin{array}{c}2 \\
\text { PUBLICADAS EM } \\
2013 \text { E } 2014\end{array}$ & & $\begin{array}{c}14 \\
\text { PUBLICADOS ENTRE } \\
1976 \text { E } 2013\end{array}$ \\
\hline
\end{tabular}




\begin{tabular}{ccccc}
\hline PPL 10 & 6 & 2 & 1 & 8 \\
$(2016)$ & PUBLICADOS & PUBLICADA EM 2011 & PUBLICADA & PUBLICADOS ENTRE \\
& ENTRE 1999 E 2009 & E 2009 & EM 2014 & 1973 E 2015 \\
\hline Total & 30 & 10 & 11 & 77 \\
\hline \multicolumn{2}{c}{ Fonte: elaboração dos pesquisadores }
\end{tabular}

Entretanto, na área de Química há uma ocorrência maior de indicação de lacunas e, da mesma forma que na área de Linguística, pode ser explicado pelo fato de que esse passo é construído a partir das leituras de fontes bibliográficas. Nesse sentido, é possível perceber que os autores dos projetos de Química se apoiam mais em artigos de periódicos que foram produzidos, em sua maioria, num período de quinze anos, com algumas exceções, levando em consideração o ano de elaboração dos projetos, como pode ser visto na Tabela 3.

Nesse caso, parece-nos que os autores, embora demonstrem conformidade com algumas pesquisas prévias, fazem leituras bibliográficas em busca de lacunas, buscando lançar o olhar com alguma criticidade para o objeto de pesquisa. Com base nisso, parecenos que essa opção pelo artigo pode ser decorrente do próprio fazer científico da área, que, por trabalhar com experimentos, tem uma urgência em mostrar e encontrar resultados recentes, que, nesse caso, raramente são publicados em livros.

Tabela 3 - Tipos de fontes bibliográficas mais utilizadas como embasamento de pesquisa na área de Química

\begin{tabular}{|c|c|c|c|c|c|}
\hline PROJETO & ARTIGO & TCC & DISSERTAÇÃO & $\begin{array}{c}\text { DOC. } \\
\text { OFICIAL }\end{array}$ & LIVRO \\
\hline $\begin{array}{c}\text { PPQo1 } \\
(2014)\end{array}$ & $\begin{array}{c}9 \\
\text { PUBLICADOS } \\
\text { ENTRE } 2004 \text { E } 2010\end{array}$ & $\begin{array}{c}1 \\
\text { PUBLICAD } \\
\text { O EM } 2014\end{array}$ & $\begin{array}{c}1 \\
\text { PUBLICADA EM } \\
\mathbf{2 0 1 3}\end{array}$ & & $\begin{array}{c}1 \\
\text { PUBLICAD } \\
\text { O EM } 2010\end{array}$ \\
\hline $\begin{array}{c}\text { PPQo2 } \\
(2016)\end{array}$ & $\begin{array}{c}4 \\
\text { PUBLICADOS } \\
\text { ENTRE } 2007 \text { E } 2013\end{array}$ & & & $\begin{array}{c}1 \\
\text { SEM DATA DE } \\
\text { PUBLICAÇÃO }\end{array}$ & \\
\hline $\begin{array}{c}\text { PPQo3 } \\
(2018)\end{array}$ & $\begin{array}{c}16 \\
\text { PUBLICADOS } \\
\text { ENTRE } 2006 \text { E } 2018\end{array}$ & & & & $\begin{array}{c}1 \\
\text { PUBLICAD } \\
\text { O EM } 199\end{array}$ \\
\hline $\begin{array}{c}\text { PPQo4 } \\
(2013)\end{array}$ & $\begin{array}{c}14 \\
\text { PUBLICADOS } \\
\text { ENTRE } 1973 \text { E } 2013\end{array}$ & & $\begin{array}{c}1 \\
\text { PUBLICADA EM } \\
\mathbf{2 0 0 4}\end{array}$ & $\begin{array}{c}1 \\
\text { PUBLICADO } \\
\text { EM } 2008 \\
\end{array}$ & $\begin{array}{c}1 \\
\text { PUBLICAD } \\
\text { O EM } 1995\end{array}$ \\
\hline $\begin{array}{c}\text { PPQo5 } \\
(2014)\end{array}$ & $\begin{array}{c}17 \\
\text { PUBLICADOS } \\
\text { ENTRE } 1983 \text { E } 2014\end{array}$ & & $\begin{array}{c}1 \\
\text { PUBLICADA EM } \\
2005\end{array}$ & & \\
\hline
\end{tabular}




\begin{tabular}{|c|c|c|c|c|c|}
\hline $\begin{array}{c}\text { PPQo6 } \\
(2016)\end{array}$ & $\begin{array}{c}12 \\
\text { PUBLICADOS } \\
\text { ENTRE } 2002 \text { E } 2016\end{array}$ & & & & \\
\hline $\begin{array}{c}\text { PPQo7 } \\
(2016)\end{array}$ & $\begin{array}{c}11 \\
\text { PUBLICADOS } \\
\text { ENTRE } 2009 \text { E } 2015\end{array}$ & & & & \\
\hline $\begin{array}{c}\text { PPQo8 } \\
(2016)\end{array}$ & $\begin{array}{c}7 \\
\text { PUBLICADOS } \\
\text { ENTRE } 2007 \text { E } 2016\end{array}$ & & & & \\
\hline $\begin{array}{c}\text { PPQo9 } \\
(2016)\end{array}$ & $\begin{array}{c}16 \\
\text { PUBLICADOS } \\
\text { ENTRE } 1987 \text { E } 2016\end{array}$ & & $\begin{array}{c}1 \\
\text { PUBLICADA EM } \\
2005\end{array}$ & $\begin{array}{c}1 \\
\text { PUBLICADO } \\
\text { EM } 2013\end{array}$ & \\
\hline Total & 106 & 1 & 4 & 3 & 3 \\
\hline
\end{tabular}

Assim como o passo "Indicando lacunas de pesquisa", o passo "Relatando pesquisas prévias” está relacionado à leitura de fontes bibliográficas, pois tem por base demonstrar o que tem sido pesquisado recentemente na área de interesse e sobre o objeto da pesquisa. Desse modo, relatar pesquisas prévias sobre o tema de pesquisa é uma maneira de mostrar que o estudo tem pertinência na área, que é possível de ser realizado. Neste passo, os autores da seção tendem a relatar pesquisas anteriores que trabalhem a mesma temática, evidenciando como foi realizada a pesquisa e as conclusões nelas obtidas, servindo de gancho para mostrar o motivo da sua própria proposta de pesquisa, o qual, muitas vezes, é relacionado ao apontamento de lacunas.

Semelhante à área de Linguística, esse passo é realizado em 4 dos 9 projetos de modo a apontar pesquisas semelhantes à que será proposta e que podem servir de base para a nova pesquisa. Neste passo, nos projetos de Linguística, as referências são indicadas no corpo do texto e geralmente são acompanhadas de um breve relato acerca do que se trata a pesquisa, como no exemplo PPLo2, a seguir.

[PPLo2] "Dentre alguns estudos relevantes recentes, destacam-se os trabalhos de Faraco (2008), Antunes (2007), Neves (2013), Travaglia (2004), Bagno (2004), Possenti (2003), Perini (2004). Esses autores apresentam uma visão geral acerca do ensino de português no Brasil contemporâneo; discutem questões relacionadas às motivações ideológicas que impulsionam o estabelecimento de objetivos para o ensino de língua; e apresentam propostas de trabalho para o ensino de língua." 
$\mathrm{Na}$ área de Química, esse passo foi realizado em 7 projetos dentre os 9 selecionados e ocorre da mesma forma que na área de Linguística, porém, percebe-se que há menos detalhes no modo de relatar as pesquisas prévias, sendo exposta apenas uma ideia geral do que está sendo tratado nas pesquisas. Além disso, as referências não vêm indicadas no corpo do texto, sendo indicadas por números que remetem a uma numeração presente na seção de referências bibliográficas.

[PPQo7] “Diversos trabalhos têm demonstrado que o emprego do método sonoquímico possibilita a obtenção de materiais com morfologia controlada, alta pureza e distribuição estreita de tamanho em um curto período de irradiação ultrassônica [1,2].”

Nesse passo, podemos perceber que a diferença entre as áreas está no fato de a área de Química apresentar uma escrita mais sintética, enquanto a área de Linguística procede a um detalhamento da pesquisa, como uma forma de demonstrar conhecimento sobre a área e o objeto de pesquisa.

Além dos passos recorrentes semelhantes às duas áreas, outros passos, que também já haviam sido descritos em outras pesquisas, foram realizados na seção de caracterização/identificação do problema das áreas em estudo.

Tabela 4 - Passos retóricos recorrentes na seção de caracterização do problema de projetos de pesquisa da área de Química

\begin{tabular}{|l|c|}
\hline \multicolumn{1}{|c|}{ PASSOS RETÓRICOS } & QUÍMICA \\
\hline Justificando a seleção do corpus & $3 / 9$ \\
\hline Caracterizando a abordagem metodológica da pesquisa & $3 / 9$ \\
\hline Justificando a relevância da pesquisa & $7 / 9$ \\
\hline
\end{tabular}

Fonte: elaboração dos pesquisadores

Na área de Química, os passos descritos por Monteiro (2016) e Monteiro e Alves Filho (2018) relacionados à aspectos metodológicos - "Justificando a seleção do corpus" e “Caracterizando a abordagem metodológica da pesquisa” - apareceram em três projetos, 
embora sejam comumente realizados na seção destinada à metodologia. E o passo "Justificando a relevância da pesquisa", apontado por Silva (2015) e Alves Filho (2018), apareceu em 7 projetos, e, a partir de Motta-Roth e Hendges (2010), entendemos ser um passo mais típico da seção de justificativa, já que essa seção "serve para demonstrar a relevância, a originalidade e/ou aplicabilidade do projeto”.

No que diz respeito à ocorrência desses passos na seção em análise, pode-se inferir que acontece pelo fato de os projetos da área de Química não apresentarem uma seção destinada à introdução. Dessa forma, a seção de caracterização do problema serve como uma apresentação, que engloba um resumo do que será abordado ao longo do projeto. E, como consequência, pela ausência da seção de justificativa, a relevância é indicada também na seção inicial.

Tabela 5 - Passos retóricos recorrentes na seção de identificação do problema de projetos de pesquisa da área de Linguística

\begin{tabular}{|l|c|}
\hline \multicolumn{1}{|c|}{ PASSOS RETÓRICOS } & LINGUÍSTICA \\
\hline Indicando indagações da pesquisa & $8 / 9$ \\
\hline Inserindo-se numa área de pesquisa & $3 / 9$ \\
\hline
\end{tabular}

Fonte: elaborada pelos pesquisadores.

Na área de Linguística, a seção de identificação do problema de pesquisa é construída de modo a levantar questionamentos que possivelmente serão respondidos com a realização da pesquisa. Por isso, a partir das análises, foi observado que em 8 dentre os 9 projetos realizaram o passo "Indicando indagações da pesquisa”. Este passo faz questionamentos, geralmente, ao final da seção, como forma de demonstrar o que será feito/solucionado com a realização da pesquisa. Esse passo atesta o que foi colocado por Barros (2005), Gil (2002) e Motta-Roth e Hendges (2010), os quais afirmam que o problema de pesquisa deve ser construído em forma de pergunta, indagação que será respondida com a realização da pesquisa. Em contrapartida, na área de Química não há a presença de indagações e o problema de pesquisa é pautado na tentativa de solucionar lacunas de pesquisas anteriores.

Outro passo que apareceu na área de Linguística foi o "Inserindo-se numa área de pesquisa”, já proposto por Rio Lima (2015). Nesse passo o pesquisador demonstra 
claramente a linha de pesquisa na qual irá se situar, e, segundo Rio Lima (2015), é comumente feito por pesquisadores iniciantes que precisam demonstrar a linha de pesquisa na qual o trabalho será realizado.

Diante de nossas discussões, podemos perceber que há muitas divergências entre as áreas de Linguística e Química quanto à maneira como a seção de identificação/caracterização do problema é realizada. Para tanto, essa divergência entre as áreas pode ser explicada a partir dos tipos de fazer história (a história-resumo; a história propagandística; a história crítica e a historiografia), propostos por Koerner (2014), os quais já foram explicitados neste trabalho, e que estão diretamente relacionados com o fazer científico.

Nesse sentido, na área de Linguística há uma forte tendência em se fazer a história-resumo, reforçando-se a ideia de que as teorias e suas respectivas metodologias já alcançaram um patamar teórico relativamente estável. Isso possibilita uma reprodução dos grandes feitos dos nomes consagrados das áreas teóricas, ressaltando que o quadro teórico já foi suficientemente delineado para que outros membros da corrente possam conduzir as suas investigações a partir de pressupostos já estabelecidos. O que se faz nesse tipo de história é uma compilação dos fatos de forma linear, em que o presente representa um avanço em relação ao passado. Essas histórias-resumos consideram a evolução da área da Linguística, mostrando que os avanços e os resultados teóricos são frutos de atividades desenvolvidas anteriormente e são baseados na história de grandes linguistas do passado. Esse tipo de história pode ser claramente visto nos passos que têm por base a leitura de fontes bibliográficas, como "relatando pesquisa prévia" e "indicando lacuna” já que se costuma relatar o que já se sabe, sem um viés crítico.

Já na área de Química há uma semelhança com a história-crítica, porém com algumas ressalvas. A história-crítica é mostrada de forma menos partidária, não interessa aqui defender teorias ou metodologias, mas sim mostrar o todo, ou seja, que as teorias e os métodos que se tem atualmente percorreram diversos momentos até chegar aonde chegaram, sendo resultados de estudos anteriores. Nesse tipo de história, também são abordados aspectos sociais, culturais e políticos para explicar o processo de construção 
do conhecimento, mesmo que de maneira superficial. É nesse ponto que se faz uma ressalva, pois essa contextualização não é feita de maneira explícita na área de Química.

O que se quer mostrar com essa discussão é que não existe área do conhecimento que seja melhor que outra, mas sim que são orientadas por diferentes modos de olhar a ciência, por diferentes concepções de escrita e leitura de gêneros adotadas por cada área.

\section{Considerações finais}

Os resultados das análises permitiram que compreendêssemos como a seção de identificação/caracterização do problema é realizada em diferentes áreas do conhecimento, como na área de Linguística e Química, através da análise de passos retóricos, já que nessa pesquisa optamos por não incluir a análise de movimentos retóricos. Nesse sentido, dez passos retóricos foram encontrados nas amostras analisadas, sendo cinco comuns às áreas de Linguística e Química. Dentre esses cinco passos em comum, "apresentando objetivos" foi o mais representativo nas duas áreas, o que pode ser justificado pela necessidade de demonstrar o que será feito na pesquisa proposta, isto é, demonstrar a relevância da pesquisa.

Outra descoberta que merece atenção é a relação que o passo "indicando lacuna" pode ter com os tipos de referências bibliográficas utilizadas nas duas áreas, já que é um passo baseado nas leituras feitas pelos autores dos projetos. Na área de Química, as referências, em sua maioria, são de artigos científicos, o que demonstra que é feita uma leitura com o intuito de investigar o que ainda não foi investigado. Já na área de Linguística, nas referências, embora contenham um número considerável de artigos científicos, há um grande número de livros e/ou capítulos de livros, o que indica uma leitura mais pacífica, com o objetivo de ler para resumir, demonstrando que se tem domínio da teoria da área.

Um ponto importante em nossas descobertas é o modo como a seção foi construída nas duas áreas, o que revelou aspectos que são mais valorizados em uma e outra área. Na área de Linguística, a seção de identificação do problema é construída 
direcionada a um questionamento que será respondido com a realização da pesquisa, enquanto na área de Química não há ocorrência de nenhum questionamento, mas sim indicações de problemas em estudos anteriores que serão solucionados com a proposta de pesquisa.

Outra descoberta que merece destaque é o fato de os passos retóricos aparecerem tanto na seção em estudo quanto em outras seções que compõem o projeto, como visto em trabalhos anteriores (ALVES FILHO, 2018; MONTEIRO; ALVES FILHO, 2018; MONTEIRO, 2016; SILVA, 2015), revelando que a seção de identificação/caracterização do problema pode servir, muitas vezes, como uma espécie de introdução, isto é, uma forma de mostrar um panorama da pesquisa, que inclui apresentação de objetivos, de aspectos metodológicos, da justificativa de relevância e das pesquisas prévias.

Diante disso, os passos retóricos encontrados, embora já tivessem sido descritos em pesquisas anteriores, mostraram que a área de Linguística apresenta aspectos mais subjetivos e empíricos enquanto a área de Química possui mais objetividade e é baseada em pesquisas anteriores. Além disso, essa análise se mostrou importante para desmistificar a ideia de que há uma área do conhecimento melhor do que a outra, evidenciando que há apenas uma diferença do fazer científico, que acarreta numa diferença de escrita da seção de caracterização/identificação do problema e do gênero como um todo.

Com essa pesquisa, pudemos ter uma noção das diferenças existentes entre as áreas de Linguística e Química, sobretudo com relação a como o olhar do pesquisador é direcionado no momento em que se propõe a planejar uma pesquisa. Entretanto, para que se tenha melhores resultados, uma análise com um corpus mais extenso e com uma investigação que dê conta de conversar com os usuários do gênero se faz necessária, tanto nas áreas em análise como em outras áreas do conhecimento.

\section{Referências}


ALVES FILHO, Francisco. Como mestrandos agem retoricamente quando precisam justificar suas pesquisas. RBLA, Belo Horizonte, v. 18, n. 1, p. 131-158, 2018.

Francisco; OLIVEIRA, Meryane Sousa. A organização retórica das seções de justificativa de pré-projetos de pesquisa. Revista do Gel, v. 14, n. 1, p. 36-58, 2017.

ASKHAVE, Inger; SWALES, John M. Identificação de gênero e propósito comunicativo: um problema e uma possível solução. In: BEZERRA, Benedito Gomes; BIASI-RODRIGUES, Bernardete; CAVALCANTE, Mônica Magalhães (orgs). Gêneros e sequências textuais. Recife: Edupe, 2009. p.221-243.

BARROS, José D'assunção. O Projeto de Pesquisa em História: da escolha do tema ao quadro teórico. 2. ed. Petrópolis -RJ: Vozes, 2005. 238 p.

BAWARSHI, A; REIFF, M. Gênero: história, teoria, pesquisa, ensino. São Paulo: Parábola, 2013.

BERNARDINO, C. G. Depoimentos dos alcóolicos anônimos: um estudo do gênero textual. 200o. Dissertação (Mestrado em Linguística) - Universidade Federal do Ceará, Fortaleza, 2000.

BEZERRA, B. G. A distribuição das informações em resenhas acadêmicas. 2001. Dissertação (Mestrado em Linguística) - Universidade Federal do Ceará, Fortaleza, 2001. COSTA, Raquel Leite Saboia da. Culturas disciplinares e artigos acadêmicos experimentais: um estudo comparativo da descrição sociorretórica. 2015. 243 pag. Dissertação (Mestrado) - Programa de Pós-Graduação em Linguística Aplicada, Universidade Estadual do Ceará, Fortaleza, 2015.

GIL, Antônio Carlos. Como redigir o projeto de pesquisa, In: Como elaborar projetos de pesquisa. 4. ed. São Paulo: Atlas, 2002, p. 161-169.

HEERDT, Mauri Luiz; LEONEL, Vilson. Projeto de pesquisa, In: Metodologia

Científica e da pesquisa: livro didático. 5. ed. Palhoça: UnisulVirtual, 2007, p. 113 - 126.

KOERNER, E. F. K. Quatro décadas de Historiografia Linguística: estudos selecionados. Centro de Estudos em Letras: Universidade de Trás-os-Montes e Alto Douro, 2014. MONTEIRO, B. N. Organização retórica e estruturação sequencial da seção de metodologia do gênero projeto de pesquisa. 2016. 162 f. Dissertação (Mestrado 
em Letras) - Centro de Ciências Humanas e Letras, Universidade Federal do Piauí, Teresina. 2016.

; ALVES FILHO. Organização retórica da seção metodologia do gênero Projeto De Pesquisa: Uma análise de projetos na área de Linguística. Linguagem em Foco. v.10. N. 1, 2018, p. 13-26.

MORENO, A. I., \& SWALES, J. Strengthening move analysis methodology towards bridging the function-form gap. English for Specific Purposes, v.50, 2018, p. 40-63.

MOTTA-ROTH, Désirée; HENDGES, Graciela R. Produção textual na universidade. São Paulo: Parábola Editorial, 2010.

OLIVEIRA, R. F. Gênero artigo acadêmico experimental: um estudo comparativo da organização retórica em diferentes culturas disciplinares. 2016. 203 f. Dissertação (Mestrado em Letras) - Centro de Ciências Humanas e Letras, Universidade Federal do Piauí, Teresina. 2016.

RIO LIMA, C. A. Movimentos retóricos na seção de fundamentação teórica de projetos de pesquisa na subárea de Linguística. 35.p, ago de 2015. \{não publicado\}

SILVA, C. R. B. Movimentos retóricos da seção de justificativa de projetos de pesquisa da área de história. Revista Ininga, v. 2, p. 33-53, 2015.

SWALES, J. Genre Analysis: English in academic and research settings. Cambridge: Cambridge University Press, 1990.

_. Research genres: explorations and applications. Cambridge: Cambridge University Press, 2004. DOI: https://doi.org/10.1017/CBO9781139524827

TRAJANO, Juliana Sousa. O excêntrico, o primeiro, o inesperado, o adverso: uma análise retórico-discursiva dos relatos de caso na literatura médica. 2012. 199 f. Dissertação (Mestrado) - Pontifícia Universidade Católica do Rio de Janeiro, Departamento de Letras, 2012.

Recebido em 27/06/2019.

Aprovado em 28/12/2019. 